\title{
A Competency-Based Technical Training Model That Embraces Learning Flexibility And Rewards Competency
}

Lee Yasinski, Red Deer College, Canada

\begin{abstract}
Today's adult learners are continuously searching for successful programs with added learner flexibility, a positive learning experience, and the best education for their investment. Red Deer College's unique competency based welder apprenticeship training model fulfills this desire for many adult learners.
\end{abstract}

Keywords: Competency-Based Technical Training; Adult Learners; Student-Centered Learning

\section{INTRODUCTION}

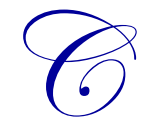

ompeting in today's oil and gas-based economies requires countries to possess more than merely a large reserve of either natural resource. Alberta's competiveness and innovation in this field can be attributed to a proven educational system insistent upon the highest standards of technical training for its trades people. The delivery of adult technical training in the trades exists worldwide using various delivery models. Alberta Apprenticeship specifies the prerequisites for a worker to be certified in Alberta's trades. Welding apprenticeship training at Red Deer College utilizes a unique delivery model entailing competency - based apprenticeship training. Re-evaluation of work's future by leading global authorities reveals "changes in the way students are being educated for work" and "the demands [placed] on workers in the knowledge age will force a major shift towards learnercentered organisational development strategies" (Kostos, 2006, p. 75). This competency-based apprenticeship training delivery model is underpinned by a blend of both teacher and student-centered learning, which requires "new policies and practices that enable and support learners as they re-focus their careers into a new world of work" (p. 75). One benefit of student-centered learning is that adult learners have an opportunity to complete their technical training early and re-enter the workforce based on proven competency.

\section{THE ALBERTA APPRENTICESHIP}

Apprenticeship in Alberta is a combination of work-site experience and technical training in a trade. It is a three-way agreement between an apprentice (worker), employer, and Alberta Apprenticeship. Depending on the trade, completion of an apprenticeship program lasts between one and four years, and apprentices spend approximately eighty percent of their time learning on-the-job from a qualified tradesperson (journeyperson). The remaining time is spent at a college or technical institute learning the theories, technologies, and skills of their trade (technical training). Apprentices earn a wage while working on the job, relative to their fellow journey people. As the apprentice completes each year of training, he or she receives a pay increase, again based on the standard rate of journey people in their respective trades. Upon completing a program, candidates receive an Alberta Journeyperson Certificate that fulfills Alberta's superior industry trade standards. There are approximately fifty designated trades in Alberta, and welding is a compulsory trade among them; therefore, an individual must be a journeyperson welder or indentured in the Apprenticeship Program of Welding (welding apprentice). The Alberta government primarily funds apprenticeship technical training (institute's requirements for delivery), although students pay for textbooks and a nominal registration and institutional fee. Furthermore, the program features a stringent policy mandating the documentation of attendance (Government of Alberta, 2012). 


\section{STUDENTS AND REQUIREMENTS}

Apprentices are adult learners ranging in age from their late teens to fifties who attend eight weeks of technical training while balancing their daily lives. Students often struggle to maintain their standard of living since few receive any wages during training. It is common for up to forty percent of a class to work beyond class hours to support their families and lifestyles. Entrance prerequisites allow for classes catering to a diverse range of academic abilities and work skill-sets, coupled with additional student challenges unique to each class.

Students who desire to enter into a welder apprenticeship agreement must meet one of the following minimum educational requirements: completion of English 10-2 and Math 10-3 (both of which are lower level tenth grade courses), posses a General Educational Diploma (GED), or complete the Alberta Apprenticeship and Industry Training entrance exam for welding (twenty-two questions focused on English, reading, and comprehension; fifty on math; and twenty-eight on science) with a passing score of seventy percent or higher. Ideally, a student should enter the welding trade possessing an Alberta High School Diploma having completed English 30-2, Math 30-3, and Physics 20 (or alternatively Chemistry or Science 20), in addition to related courses in career and technology studies (Government of Alberta, 2012).

For each year of the apprenticeship welding apprentices are required to pass both institute and government exams, and must finish their technical training at Red Deer College with a score of at least sixty-five percent before proceeding to complete that respective year's government exam. Students must score a minimum of seventy-percent on the government examination or else remain at their current (first, second, or third year) apprenticeship level.

\section{INSTRUCTOR}

Most college or technical institutes offering the apprenticeship program require instructors to possess a minimum of five to ten year's experience as a journeyperson, supplemented by trade-related training (such as an engineering degree) or post-secondary (college or university level) education. Competency based delivery requires a well-rounded, enthusiastic, techno-savvy instructor with proven skills in content creation, presentation, management, and adult learning curricula. However, among these characteristics, Bryson and Hand (2007) rightly assert that enthusiasm is the most critical and "a prerequisite for student engagement" (p. 357). A correlation exists between student achievement and an instructor's successful adaptation to constantly changing classroom dynamics, such as variations in academic ability, ethnic background, and learning style, in addition to student disabilities, real life experiences, and personal challenges. A welding instructor therefore must deliver all curriculum components at any given time, to every individual or group throughout a course's duration with enthusiasm. This requires welding instructors to possess not only knowledge of several different welding processes but also to demonstrate proficiency in math, blue-print reading, pattern development, metallurgy, history, and codes. At institutes offering a more traditional form of training, content experts are often expected to address subjects such as math and metallurgy. Indeed, as Sinclair and Mitchell (2000) note, "good teachers are those who know what it is like out in the field" (pp. 5-22). A sentiment mirrored by several students in their interviews, who stressed the importance of practical knowledge over theory.

\section{A COMPETENCY-BASED MODEL EMBODIES FLEXIBILITY}

The Red Deer College welding department has provided technical training to welders using a competencybased delivery model for over ten years. A total of six hours each day is devoted to technical training for eight weeks; each six-hour day is divided into a shop and theory component.

Regarding the shop component, the Alberta Apprenticeship curriculum outlines the amount of time and practical skill level required for students to progress to the next year of an apprenticeship, and the shop component combination of training on-the-job and technical training functions ensure this. On-the-job training varies according to each student's degree of experience in the field and with different welding processes (equipment). As Christman (2012) indicates, "On-the-job training [that teaches] job-specific skills is an important dimension [of an] apprenticeship program" (p. 26). Thus, the skill set for students working in manufacturing differs from those specializing in industrial maintenance or the petroleum industry. 
Red Deer College's shop component maintains a ratio of one instructor for every twelve students, resulting in increased safety, time allotted to demonstrations, and sufficient opportunities for self-evaluation and skill advancement. The yearly practical test welds (projects) are either evaluated visually or by using a combination of both visual examination and destructive testing (guided bend test). The evaluation criteria are detailed concerning the expected visual appearance and soundness of the weldment (cleanliness throughout its cross-section). Students unable to meet the training's practical requirements must repeat the level if they wish to continue in the trade. Those who fail their first attempt for any given year are typically successful upon their second.

The theory component of the model is delivered in two ninety-minute blocks daily, with one classroom session and another in the learning commons area. The classroom session generally embodies Kember's (1997) teacher-centered/content-oriented approach, which focuses on "the communication of defined bodies of content or knowledge" (p. 264). Classroom time is used to ensure that the curriculum is covered in its entirety using a variety of delivery formats, occasionally in tandem, including PowerPoint presentations, videos, whiteboards, and props. Furthermore, the use of clickers, question and answer sessions, mind mappings, flowcharts, and quizzes reinforce and validate student progress and understanding. By sharing their experience and knowledge, instructors provide a clear path for learners to understand concepts and information. Hence, the instructor is akin to a lead ant with others (students) following it towards a food source (concept), who then demonstrates the quantity to break off (defining details), how it should be loaded (understanding), and the return path to the ant hill for storage (retention). This cycle is repeated until the food source is deconstructed according to all relevant details, subsequently facilitating the complete understanding of a concept.

The second ninety-minute block, which is spent in the learning commons area, draws upon Kember's "student-centered/learning-oriented approach, focusing on student learning while taking a developmental approach towards students and their conceptualization of knowledge; in other words, emphasis is placed on students" acquisition of knowledge rather than lectures" (p. 264) as students take ownership of the learning process. Spaces for both group and individual study are available in the commons, as well as internet access, enabling students to use school equipment or personal devices such as i-pads, smart phones, or laptops to enhance their studies. Similarly, instructors are given a small cubicle where exams can be reviewed or student issues addressed in a confidential manner.

Students may choose to work in groups or alone and can cover content at their own pace, allowing learners to concentrate on difficult subjects and minimalize emphasis on less troublesome topics. This is in agreement with McLean and Gibbs' (2010) assentation that a flexible curriculum should, "Allow time for independent learning and pursuing areas of interest" (p. 228). Students collaborating (social networking) implement personal learning preferences and share life experiences to achieve a mutual understanding of concepts. In parallel, an instructor is close by and readily available to provide learners with access to their wealth of knowledge and personal experience. By switching from teacher to student-centered learning daily, students are revitalized and prepared to engage in active learning. In this scenario, the lead ant (instructor) merely points his followers (students) in the food source's (concept's) general direction, as they work individually or in groups to break food (the defining details) off, determine how it should be loaded (understood through the sharing of learning experiences and styles), and finally returned to the ant hill for storage (retention). The lead ant's role is to oversee the process and provide assistance if needed. No finite cycle exists since each group or individual deconstructs and retains information using a technique specific to his or her needs.

\section{TESTING}

The Red Deer College welding department possesses a large on-line test bank for each year of technical training, providing students with the flexibility to approach topics at a rate relative to their understanding of each one. Additionally, this allows for early exit while maintaining the programs quality and security. Test questions are selected from pools directly linked to the curriculum's objectives; a given percentage of questions are drawn from each pool randomly, and the created assessments are never alike. The curriculum is currently being delivered using Blackboard 9.1 as the assessment management program. Course content can be accessed through the college website, which contains a map illustrating each content area and its supporting module, review, and supervised exams. Students with Internet access can finish modules and review exams at any time, although supervised exams must be taken in a testing room, which is accessible from the learning commons area. 


\section{STUDENT RECOGNITION}

Red Deer's training and learning delivery system is unique, and the college has gained recognition throughout Canada as a choice institute for technical training in the welding trade. Through word of mouth, the school has attracted students from distant locations such as New Brunswick, Newfoundland, Nova Scotia, and Prince Edward Island. Students with learning difficulties, or those who have struggled at other institutes, often find this delivery system provides sufficient flexibility to facilitate a positive learning experience. As noted by McLean and Gibbs, institutions must recognize, "Students as individuals" and "embrace student diversity and [their] individual learning needs" (p. 227). Indeed, the author believes that Red Deer's system accomplishes this goal by catering to highly self-motivated students, or those supporting families, who welcome an opportunity to complete their studies early and re-enter the workforce promptly.

\section{CONCLUSION}

The competency based technical training model presented in this article is an optimal delivery system, affording adult learners greater flexibility in balancing their studies and personal responsibilities. This is accomplished by allowing students to study at their own pace using both face-to-face and electronic social networking to complete their studies promptly and secure employment. Alberta Apprenticeship has established itself as an educational institution with high standards, whose welding journey people have gained worldwide recognition. Furthermore, it has played an undeniable role in strengthening Alberta's economy, competitiveness, and innovation in the global oil and gas industry. Alberta's apprenticeship and industry training system has aptly responded to labor market conditions by developing a highly skilled workforce capable of competing on both national and international levels.

\section{AUTHOR INFORMATION}

Lee Yasinski is a professor of welder technical training at Red Deer College and formally taught fabrication studies at the high school level. He has attended Okanogan University College, Medicine Hat College, the Northern Alberta Institute of Technology, and Vermilion College. Lee Yasinski, Red Deer College, 100 College Boulevard, Box 5005, Red Deer, AB, Canada, T4N 5H5. E-mail: lee.yasinski@rdc.ab.ca

\section{REFERENCES}

1. Bryson, S., \& Hand, L. (2007). The role of engagement in inspiring teaching and learning. Innovations in Education and Teaching International, 44(4), 349-362.

2. Christman, S. (2012). Preparing for success through apprenticeship. Technology and Engineering Teacher, September, 22-28.

3. Government of Alberta. (2012). Apprenticeship and industry training. Retrieved from http://www.tradesecrets.alberta.ca/

4. Kember, D. (1997). A reconceptualisation of the research into university academics' conceptions of teaching. Learning and Instruction, 7(3), 255-275.

5. Kostos, C. (2006). Learning in the knowledge age, where the individual is the centre of learning strategy and organisational success. Australian Journal of Adult Learning, 46(1), 75-83.

6. McLean, M., \& Gibbs, T. (2010). Twelve tips to designing and implementing a learner-centred curriculum: Prevention is better than cure. Medical Teacher, 32, 225-230.

7. Sinclair, B. J., \& Mitchell, R. (2000). Competency-based versus traditional cohort-based technical education: A comparison of students' perceptions. Journal of Career and Technical Education, 17(1), 5-22. 